\title{
The Effect of Creativity in Inquiry-Problem Based Learning Base on Multimedia to the Student's Achievement and Generic Ability on Topic Chemical Bonding
}

\author{
Retno Dwi Suyanti \\ \{dwi_hanna@yahoo.com\} \\ Chemistry Departemen of State University of Medan
}

\begin{abstract}
The objectives of this research are: (1) to determine differences in student's achievement with Inquiry based Learning in Multimedia and Conventional Learning. (2) To determine differences in student's achievement who have high creativity and low creativity. 3. To determine the interaction between Inquiries based learning in multimedia with the level of creativity in improving student's achievement. The sample was taken by a cluster random sampling of two classes, which the first class as experimental class using inquiry base on multimedia and second class as control class using conventional method. The instrument consists of 30 items in multiple choice questions that have been validated and reliable. The results of research are: there are differences in physical students learning outcomes are taught by Inquiry based learning in multimedia and Conventional Learning. There is a difference in student's learning outcomes that have high Creativity and Low Creativity. There is no interaction between the Inquiry based Learning in multimedia with student's level of Creativity in improving learning outcomes chemistry. The generict ability aspect which be improved from this model implementation are simbolic language, logical frame and logical inference
\end{abstract}

Keywords: Inquiry -problem Based Learning in Multimedia, Level of Creativity, generic ability.

\section{Introduction}

Education is a conscious effort to develop concern human maturity, either intellectual maturity, social or moral maturity. Education must also be able to realize the learning condition in which students actively develop their potential for themselves to have the spiritual strength, self-control, personality, intelligence, lofty character, also the necessary skills that is needed in their society, nation and state (Department of national education, 2003). As professional educators, certainly, the problems encountered are not hampered but a challenge to be more creative and innovative.

In order that, for that numerous attempts have been made to improve the learning outcomes of students in studying chemistry, including the maximize use of some media. In research of Silaban, R. (2010) with the title the influence of the use of Macromedia Flash, Power point Program and concept map Against the results of a Study On the subject of Chemical Hydrocarbons can be inferred that there is an increase in chemical study results of 
students taught using macromedia flash, PowerPoints and media concept map. (Silaban, R. 2010) Other studies that examine the effectiveness of the use of media, namely Sialagan, M (2009) entitled the use of computer-based Media with Microsoft Office Power point On the subject of Hydrocarbons which prove that the student's activities in PBM (teaching and learning) after using media computers increases compared to other media. In addition to exploiting the media learning, other things that are not as important in the learning process is the selection of the learning strategies.

Learning strategies is an art and science to bring learning such that the learning objectives can be achieved efficiently and effectively (t. Raka Joni, 1980). Inquiry learning strategy is a strategy whereby the process of finding by students is the bottom line. In this activity contained activities meaningful to produce findings that students no longer obtained from the results of a given set of facts, but rather results from the fact that it faces (Roestiyah, 2001). Such is the case with research results (Sipayung, d. a. 2011) concluded that the results of the learning of students who are taught using the inquiry learning of web-based media and wheel higher than the results of the student learning using learning expository without media.

\section{Method}

\subsection{Location and time research}

The research was conducted in post graduate grade 2 nd in academic year 2018/2019. The time of this research was conducted on July 2018 until September 2018.

\subsection{Research population and sample}

Population of this research was all student of post graduate school in chemical education. The sample was chosen randomly in this research were two class in grade II in reguler and executif class. One class as experiment class that have been taught by inquiry learning base on multimedia and another class was taught by conventional method.

\subsection{Research variable}

There are 3 variables of this research which have been used to reach the goal of the research they are:

1Independent Variable: Inquiry base on multimedia.

2Dependent Variable: student's Generic skill and student's creativity.

3Control Variable: Learning material that is used in both of experiment and control class is chemical bonding. The time allocation for experiment and control class is same and also teacher competence is same in both of class.

\subsection{Research instrument}

Instrument test was used to determine how far the student understands of the material that has been taught by the researcher. The instruments tests in this research are multiple choice consist of 30 items and questionnaire for creativity test consist of 30 items with 4 criteria.

Then the data obtained from the instrument test would be analyzed to determine the improvement of student's achievement. 


\subsubsection{Instruments test}

The instrument is tested before using to analyze the quality. The test including validity test, reliability test, difficulty level test, different index test and testing by using statistic. Statistic is a tool that very important to use in determining the way to collecting data, presenting, analyzing, and concluding the result of data.

\subsubsection{Validation tests}

Validity relates to the ability to measure exactly something to be desired. The correlation coefficient, item can be declared invalid matter if $r_{\text {count }}>r_{\text {table }}, r_{\text {count }}$ value matched with rtable product moment at $5 \%$ significance.

\subsubsection{Reliability test}

Reliability tests related to the problem of trust. To test the reliability of the test used Kuder Richardson formula 20 or better known as KR-20. To interpret the price of those consulted about the price of the price table to table $\mathrm{r}$ criticism Product Moment with $\alpha=0.05$, the matter stated reliable if $r_{\text {count }}>r_{\text {tabel }}$.

\subsubsection{Level of difficulty problem}

Difficulty level of questions addressed by the magnitude of the problem, namely by showing hard numbers simply a matter. Questions are good if the problem is not easy or not too difficult.

\subsubsection{Distinguish power problem}

Distinguishing matter is something to distinguish between students who are good (highly capable) with the stupid students (low-ability). The analysis aims to assess different power those items in order to know about the ability to distinguish students who belong to afford (high performance) with students classified as less (weak performance).

\subsection{Research design and research procedure}

Research design that is used for this research is experiment with two sample class where the first sample class A experiment class and the second sample class B as control class. The design of this research is as shown in the table below:

For the first treatment both of class is given pre-test. Giving the test intended to measure the cognitive aspects of students before and after action. After doing pre-test, for experiment class is taught by Inquiry based learning in multimedia whereas the control class is taught by conventional model with the same topic of chemical bonding. After teaching treatment, for both of sample is given post-test in order to know the achievement of students after doing teaching treatment as the evaluation of the study. The students creativity was observe duringlearning process. Then testing the hypothesis to get the conclusion 
Table 1.Research design

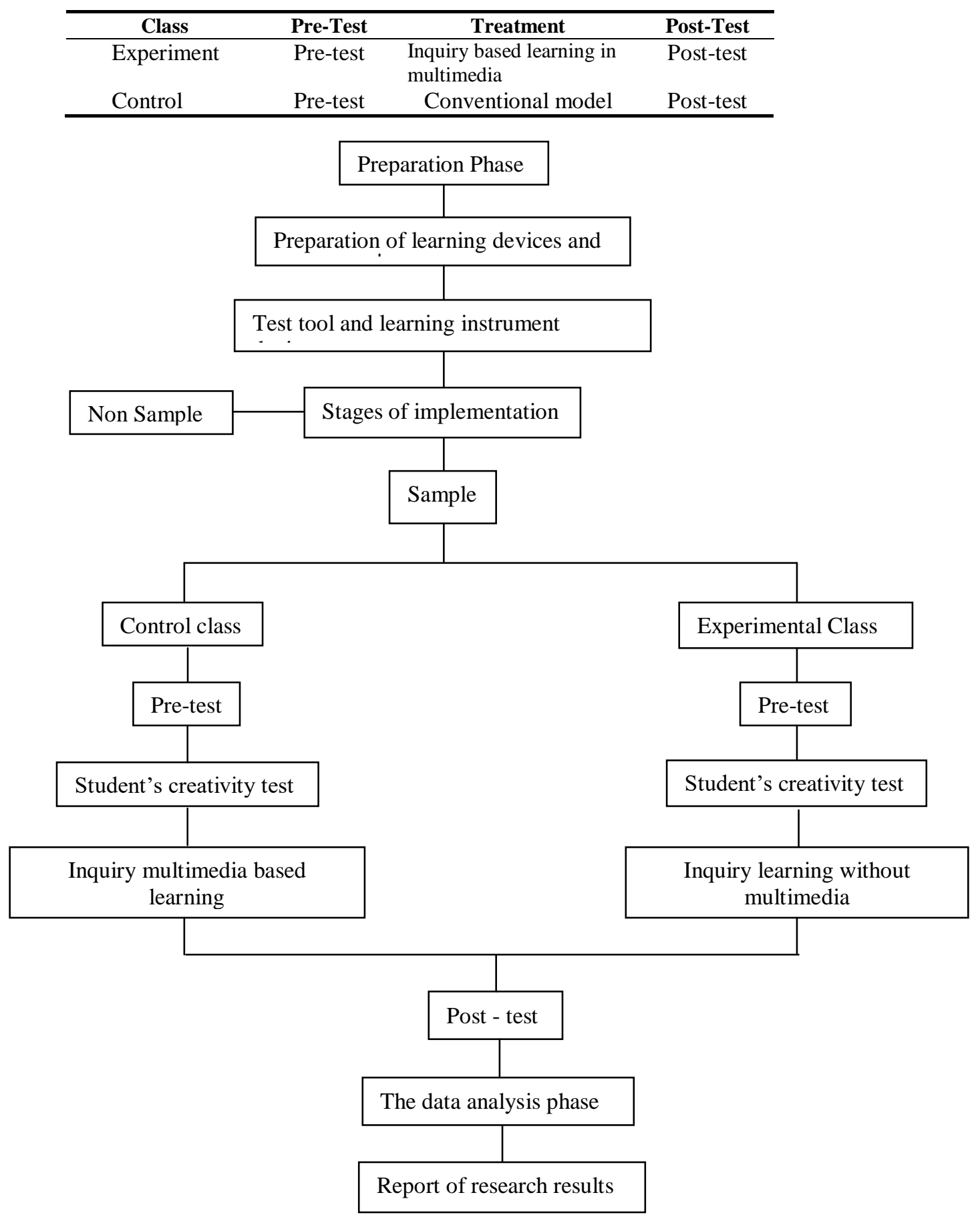


Fig 1.The overview of research design, the implementation of inquiry learning bases in multimedia to increase student's achievement and creativity in chemical bonding topic

\subsection{Technique of data analysis}

Techniques of data analysis that used are normality test, homogeneity test, normalized gain, and hypothesis. Techniques of data analysis in this research by using statistic calculation.

\subsubsection{Normality test}

Normality test of sample is used to test the normality of data distribution will be analyzed. To test the normality performed by Chi Square test $\left(X^{2}\right)$ (Arikunto, S., 2002). Normality test by using Chi Square test $\left(\mathrm{X}^{2}\right)$. Compare values of calculating with $\mathrm{h}$ significant level $(\alpha)=$ 0.05 . If $X_{\text {count }}^{2} \leq X_{\text {table }}^{2}$ so the distribution of data is normal.

\subsubsection{Homogeneity test}

Homogeneity test conducted to determine the data is homogeneous or not (Silitonga, 2011). $F_{\text {count }}$ is compared with table of frequency distribution $F_{(\alpha=0.05)}$. The sample is homogeneous if $\mathrm{F}_{\text {count }}<0.05$.

\subsubsection{Normalized gain}

According to Meltzer (in Sipayung, 2014) to calculate the student's achievement is applied formula gain normalization or $\mathrm{g}$ factor (gain score normalized).

\subsubsection{Hypothesis Test}

Based on table 4 above, then it can be described conclusions related to the research hypothesis, then the hypothesis of statistics are:

a. The first hypothesis is proposed, i.e. There are accepted Ha difference results study chemistry between students who are taught to use learning strategies inkuirimultimedia-based with students who are taught to use learning strategies, since $\alpha=0.05>\operatorname{sig} 0.0$ and $\mathrm{F}>\mathrm{F}$ count table $(52,158)$.

b. The second Hypothesis proposed Ha accepted, that there is a difference of the results between the groups studied chemistry students students who have high creativity with students who have low creativity, for $\alpha=0.05>\operatorname{sig} 0.01$ and count (119.218) F $>$ F table

c. The third Hypothesis put forward Ho accepted (Ha denied) that there was no interaction between the learning strategies and the level of creativity in influencing the result learned Chemistry student on a subject matter for bonds, since $\alpha=0.05<\operatorname{sig} 0.375$ and F calculate $(0,80)<\mathrm{F}$ interactions between the learning strategies and the learning strategies and the level of creativity in influencing the result learned.

The Student creativity can be shown by their chemsketch create :

Complex Compounds of Octahedral Shape in $\left[\mathrm{Cu}(\mathrm{CN})_{6}\right]$ or Hexacyanocopper (II) Compound

Complex compound is the compound that piled up from a central metal ion with one or more ligands and donate the pair electron to the central metal ion. The donation of ligands pair 
to the central metal ion produced coordination covalent bonding so that the complex compound is also stated coordination compound.

So, all of the complex compounds or coordination compounds are the compound that cause of the coordination covalent bonding between transition metal with one or more ligands.

Complex compounds have the relation with Lewis acid and base where Lewis acid is the compound that can be able as the receiver free electron pair and Lewis base is the compound that acted as the donator of electron pair. Complex compound can decompose become complex ion.

Complex compound have been studied and researched through the stages of reaction mechanism using the metal ions and different ligands. Ligands have the ability as the donator of the electron pair so that can be able different among monodentat, bidentate, tridentate, and polidentate.

Theory of crystal medium used to explain color and magnetic properties of hydrate transition metal salts, especially that have the central ion of transition metal with orbital d that not filled yet by the electrons.

\section{Discussion}

\subsection{Complex compounds}

Complex compound is the compound that piled up from a central metal ion with one or more ligands and donate the pair electron to the central metal ion. The donation of ligands pair to the central metal ion produced coordination covalent bonding so that the complex compound is also stated coordination compound.

Complex compounds have the relation with Lewis acid and base where Lewis acid is the compound that can be able as the receiver free electron pair and Lewis base is the compound that acted as the donator of electron pair. Complex compound can decompose become complex ion.

Complex compound have been studied and researched through the stages of reaction mechanism using the metal ions and different ligands. Ligands have the ability as the donator of the electron pair so that can be able different among monodentat, bidentate, tridentate, and polidentate.

\subsection{Octahedral compound}

The octahedral compounds suitable in a cube. Where, the octahedral have 6 ligands and have position in the central of cube's surface. In the complex octahedral, the central atom have bond with 6 donor atoms. The octahedral complex have the highest symmetry if the ligands that bond is themonodentate and monoatomic, like $\mathrm{F}-, \mathrm{Cl}-, \mathrm{Br}-$, and $\mathrm{I}-$. In the formation octahedral complex assumed there are 6 ligands monodentate that near with central atom until the certain distance when the bonds between central atom and ligands formed.

Here in this paper we have the octahedral compound that's $[\mathrm{Cu}(\mathrm{CN}) 6]$ with the IUPAC name Hexacyanocopprate (II). This compound is octahedral compound because the central atom is $\mathrm{Cu}$ and the ligands are $\mathrm{CN}$ - (Cyanide) and there are 6 (six) ligands of $\mathrm{CN}$-. Because 
$\mathrm{CN}$ - is ligand, so the name is Cyano. The picture of the complex compound of $[\mathrm{Cu}(\mathrm{CN}) 6]$ is in the following picture:

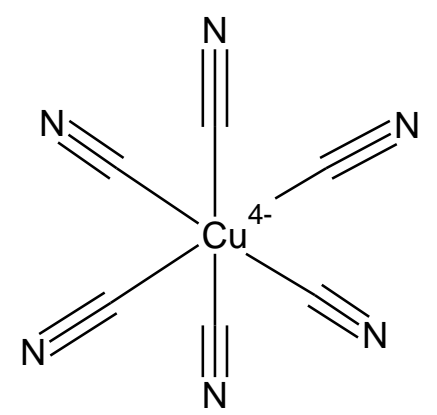

Fig. 2.Complex compound of $\left[\mathrm{Cu}(\mathrm{CN})_{6}\right]$

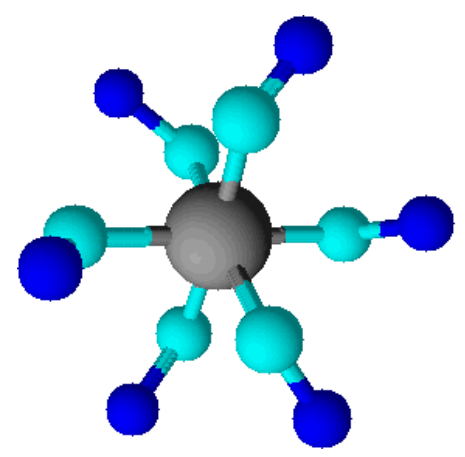

Fig. 3. Complex compound of $\left[\mathrm{Cu}(\mathrm{CN})_{6}\right]$ in $3 \mathrm{D}$

The configuration:

${ }_{29} \mathrm{Cu}^{2+}=[\mathrm{Ar}]_{18} 3 \mathrm{~d}^{7} 4 \mathrm{~s}^{2}$

Electronic configuration:

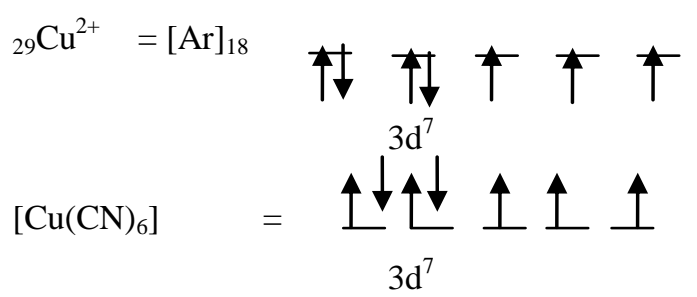

Paramagnetic

$4 \mathrm{~s}$

$d^{2} s p^{3}$

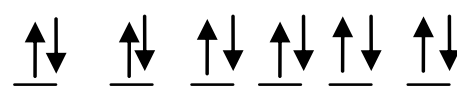


Octahedral

$\checkmark 6$ pair electrons

$\checkmark \quad 6$ ligand $\mathrm{CN}$

$\checkmark$ High spin because it $\mathrm{CN}$ is the weak ligand

$\checkmark$ Diamagnetic

Magnetic Moment

$$
\begin{aligned}
& \mu=\sqrt{n(n+2)} \\
& \mu=\sqrt{3(3+2)}=\sqrt{15} B M(\text { Paramagnetic })
\end{aligned}
$$

1. Complex compound is the compound that piled up from a central metal ion with one or more ligands and donate the pair electron to the central metal ion. The donation of ligands pair to the central metal ion produced coordination covalent bonding so that the complex compound is also stated coordination compound.

2. The octahedral compounds suitable in a cube. Where, the octahedral have 6 ligands and have position in the central of cube's surface. In the complex octahedral, the central atom have bond with 6 donor atoms.

3. The octahedral complex have the highest symmetry if the ligands that bond is the monodentate and monoatomic, like $\mathrm{F}^{-}, \mathrm{Cl}^{-}, \mathrm{Br}^{-}$, and $\mathrm{I}^{-}$. In the formation octahedral complex assumed there are 6 ligands monodentate that near with central atom until the certain distance when the bonds between central atom and ligands formed.

4. $\left[\mathrm{Cu}(\mathrm{CN})_{6}\right]$ with the IUPAC name Hexacyanocopprate (II) is the octahedral complex compound because the central atom is $\mathrm{Cu}$ and the ligands are $\mathrm{CN}^{-}$(Cyanide) and there are 6 (six) ligands of $\mathrm{CN}^{-}$. Because $\mathrm{CN}^{-}$is ligand, so the name is Cyano.

\section{Conclusion and suggestion}

\subsection{Conclusion}

1. There are differences in physical students learning outcomes are taught by Inquiry based learning in multimedia and Conventional Learning with $\alpha=0.05>\operatorname{sig} 0.0$ and $\mathrm{F}$ calculate $>$ $\mathrm{F}_{\text {tabel }}(52,158)$

2. There is a difference in student's learning outcomes that have high Creativity and Low Creativity with $\alpha=0.05>\operatorname{sig} 0.0$

3. There is no interaction between the Inquiry based Learning in multimedia with student's level of Creativity in improving learning outcomes chemistry with $\alpha=0.05<\operatorname{sig} 0.375$ and $\mathrm{F}_{\text {calculate }}(0.80)<\mathrm{F}_{\text {tabel }}$.

4. Using chemsketch and multimedia based mention improving student achievement and student generic skill in are simbolic language, logical frame and logical inference.

\subsection{Suggestion}

The research should be done for further in order to compare the result. 


\section{References}

[1] Anwar.,M.: The Effect of Active-Cooperative Learning on Science Generic Skills of Students in Chemical Kinetics Course for Prospective Teachers.Journal of Education and Practice, 5 (31), 149154 (2014)

[2] Arends, R.:.Learning to Teach :BelajaruntukMengajarBukuDua, edisike - 7.Yogyakarta: PustakaPelajar (2008)

[3] Bell , J.: Who Will Prepare Tomorrow's Science Teachers? How? Journal of Chemical Education, 74(14), 35-46 (2011)

[4] Gagne... Instructional Technology: Foundations. London: Lawrence Erlbum Associates (1987)

[5] Hake, R.:. Interactive engagement Versus Traditional Methods: A Six Thousand student survey of Mechanics Test Data for Instroductory Physisc Courses. America Journal of Physics, 66(1), 64-74 (1998)

[6] Heinich, R., Molenda , M., Smaldino, S., and Russell J... Instructional Technology and Media For Learning, $8^{\text {th }}$ Edition. New Jersey :Pearson (2005) 